\title{
Evolución y situación epidemiológica de la infección por virus de inmunodeficiencia humana y síndrome de inmunodeficiencia adquirida en Chile
}

\author{
Maritza García O. y Andrea Olea N.
}

Departamento de Epidemiología Ministerio de Salud de Chile

Recibido: 20 marzo 2008 Aceptado: 31 marzo 2008

Correspondencia a: Maritza García Ochoa maritza.garcia@minsal.gov.cl

\section{Epidemiology of human immunodeficiency virus infection and AIDS in Chile}

In Chile, the first cases of AIDS were reported 23 years ago, and since then, through December 2006, 17.235 persons have been notified with HIV infection or AIDS ${ }^{1}$. To the year 2005, there have been 5.288 fatal cases of AIDS. The last available data indicates that notification rates for AIDS and HIV infection in 2006 were 2.5 and 4.5 per 100.000 inhabitants, respectively, and mortality rate for AIDS in 2005 was 2.4 per 100.000 inhabitants. Trend analysis shows a decline in the notification rate among men, both for HIV infection and AIDS, which could be a real decrease or a sub notification bias. In Chile, like in other countries of the region, variations in the epidemiologic pattern were observed considering age group, gender, educational level and geographic distribution of the population. Currently, the Chilean Ministry of Health has implemented both a surveillance and monitoring system on line, in order to improve the quality and opportunity of the information, therefore providing an important tool to HIV infection/AIDS prevention and control strategies.

Key words: HIV, AIDS, epidemiology.

Palabras clave: VIH, SIDA, epidemiología.

Situación de la epidemia mundial y en América Latina

$\mathrm{E}$ n los últimos años, los avances en los sistemas de vigilancia epidemiológica mundial han permitido profundizar el conocimiento de la epidemia, permitiendo estimaciones más precisas del número de personas infectadas con el virus de inmunodeficiencia humana y síndrome de inmunodeficiencia adquirida (VIH/SIDA).

De acuerdo al reporte correspondiente al año 2007 del programa conjunto de las Naciones Unidas sobre infección por VIH/SIDA (ONUSIDA) y de la Organización Mundial de la Salud (OMS) ${ }^{2}$, la prevalencia mundial de infección por VIH en la población adulta ha tendido a estabilizarse siendo de $0,8 \%$, pero el número total de infectados sigue en aumento, debido a la acumulación continua de nuevas infecciones con períodos más prolongados de sobrevida, medidos en una población general en constante crecimiento ${ }^{2}$.

El número estimado de infectados por VIH en el mundo alcanzó el año 2007 a 33,2 millones, cifra que sustituye la estimación del año 2006 de 39,5 millones. La principal razón que explica esta reducción es la reciente revisión y re-evaluación de las estimaciones correspondientes a la India y cinco países de África sub-sahariana. Un porcentaje de las reducciones se debe a una atenuación en el número de nuevas infecciones, probablemente relacionada a una disminución en las conductas de riesgo. Sin embargo, el número total de personas infectadas con VIH está aumentando, debido a la incesante propagación de la infección por VIH y a la mayor sobrevida de las personas con infección por VIH/SIDA, en una población general de crecimiento constante (Tabla 1).

La incidencia mundial del VIH durante el año 2007 fue de 2,5 millones (1,8- 4,1millones) $)^{2}$, es decir, se produjeron aproximadamente más de 6.800 nuevas infecciones por día, cifra inferior a la incidencia estimada a fines de los años 90 de más de tres millones de nuevas infecciones por año. Estos datos reflejarían las tendencias naturales de la epidemia, así como son resultado de los esfuerzos de prevención ${ }^{2}$.

África sigue siendo el continente más afectado por la epidemia. Se estima que en el año 2007, 22,5 millones de las personas infectadas con VIH - 68\% del total de casos en el mundo- habitan en esta región, con cerca de 1,7 millones (1,4-2,7 millones) de nuevas infecciones en adultos y niños ${ }^{2}$.

En el mundo, en los dos últimos años, el número de personas fallecidas por enfermedades relacionadas con el SIDA se ha reducido, en parte gracias a la introduc- 
ción de la terapia anti-retroviral (TARV) altamente efectiva. El SIDA está entre las principales causas de mortalidad en el mundo y sigue siendo la principal causa de defunción en África. En el año 2007, el número estimado de fallecidos a causa del SIDA fue 2,1 millones (1,9 - 2,4 millones), de los cuales, $76 \%$ se produjo en África subsahariana ${ }^{2}$.

En América Latina la epidemia se mantiene estable y la transmisión del VIH sigue produciéndose en poblaciones de mayor riesgo de exposición, con variabilidad en los patrones de transmisión en los distintos países. En Bolivia, Chile, Ecuador y Perú, así como en varios países de América Central, el factor de riesgo de exposición más relevante es las relaciones sexuales sin protección entre varones².

El número estimado de nuevas infecciones por VIH en adultos y niños en América Latina, en el año 2007, fue 100.000 (47.000-220.000), lo que eleva a 1,6 millones el número de total de personas infectadas con VIH en esta región. De éstos, alrededor de un tercio residen en Brasil, donde, en un principio, la epidemia se concentraba, principalmente, entre hombres que tenían relaciones sexuales con hombres, para luego también manifestarse entre usuarios de drogas inyectables y, con el tiempo, extenderse a la población en general, entre la que se registra un número creciente de mujeres $^{2}$.

Se estima que aproximadamente 58.000 personas (49.000-91.000) fallecieron a causa del SIDA en nuestra región durante el año $2007^{2}$.

\section{Situación de la epidemia en Chile}

La epidemia de infección por VIH/SIDA se inició en Chile en 1984, con la notificación de seis personas, distribuidas en las regiones de Valparaíso, Bío-Bío y en la Región Metropolitana. Todos estos casos eran hombres entre 27 y 42 años de edad. En 1985, la Región Metropolitana notificó la primera mujer en el país.

La vigilancia epidemiológica de infección por VIH/ SIDA en nuestro país ha sido responsabilidad del MINSAL desde el primer caso notificado el año 1984, estando regulada por el Decreto Supremo $\mathrm{N}^{\circ} 158^{3}$ y se realiza mediante vigilancia pasiva por recolección de datos de casos notificados por el Boletín Enfermedades de Notificación Obligatoria (ENO), "Encuesta epidemiológica de caso de infección por VIH/SIDA" y certificados de defunción ${ }^{4}$.

A partir de abril de 2005, el Departamento de Epidemiología del MINSAL se hizo cargo de esta función, constituyéndose una comisión integrada por expertos de la Comisión Nacional de SIDA (CONASIDA), Instituto de Salud Pública (ISP), de las secretarias regiona-
Tabla 1. Resumen mundial de la epidemia de SIDA. Diciembre de 2007

\begin{tabular}{|c|c|c|}
\hline \multicolumn{3}{|c|}{ Personas infectadas con VIH en 2007} \\
\hline Total & 33,2 millones & $(30,6-36,1$ millones $)$ \\
\hline Adultos & 30,8 millones & $(28,2-33,6$ millones $)$ \\
\hline Mujeres & 15,4 millones & $(13,9-16,6$ millones $)$ \\
\hline Bajo 15 años & 2,5 millones & $(2,2-2,6$ millones $)$ \\
\hline \multicolumn{3}{|c|}{ Nuevas infecciones por VIH en 2007} \\
\hline Total & 2,5 millones & $(1,8-4,1$ millones $)$ \\
\hline Adultos & 2,1 millones & (1,4 - 3,6 millones) \\
\hline Bajo 15 años & 420.000 & $(320.000-380.000)$ \\
\hline \multicolumn{3}{|c|}{ Defunciones causadas por el SIDA en 2007} \\
\hline Total & 2,1 millones & $(1,9-2,4$ millones $)$ \\
\hline Adultos & 1,7 millones & $(1,6-2,1$ millones $)$ \\
\hline Bajo 15 años & 330.000 & $(310.000-380.000)$ \\
\hline
\end{tabular}

les ministeriales (SEREMI) de Salud y del MINSAL, con el objeto de definir los elementos técnicos y operativos de esta vigilancia, cuyos resultados quedaron establecidos en la Circular B51/18 del 21 de marzo de 2007, actualmente vigente ${ }^{5}$.

En este reporte se presenta la situación epidemiológica de la infección por VIH/SIDA de Chile, entre los años 1987 y 2006.

Metodología. Se analizaron las bases de datos de mortalidad del MINSAL (DEIS) entre los años 1990 y 2005 y la de infección por VIH/SIDA de la misma fuente, entre los años 1987 y 2006, que contiene toda la información proveniente de la "Encuesta epidemiológica de caso de infección por VIH/SIDA"6 . Se calcularon las tasas de incidencia y defunción por 100.000 habitantes, utilizando estadísticas de población del Instituto Nacional de Estadísticas (INE) 7 .

Para el análisis consistente de la evolución de algunas variables, se agruparon los casos de incidencia en cuatro quinquenios, desde 1987 al 2006 (equivalente a 17.192 personas). Los quinquenios corresponden a los períodos 1987-1991, 1992-1997, 1998-2001, 20022006, dejando fuera del análisis quinquenal 43 casos ocurridos entre 1984 y 1986.

\section{Resultados}

Incidencia. Entre 1984 y 2006 se han notificado 17.235 personas infectadas con VIH o SIDA. El 54\% (9.195 


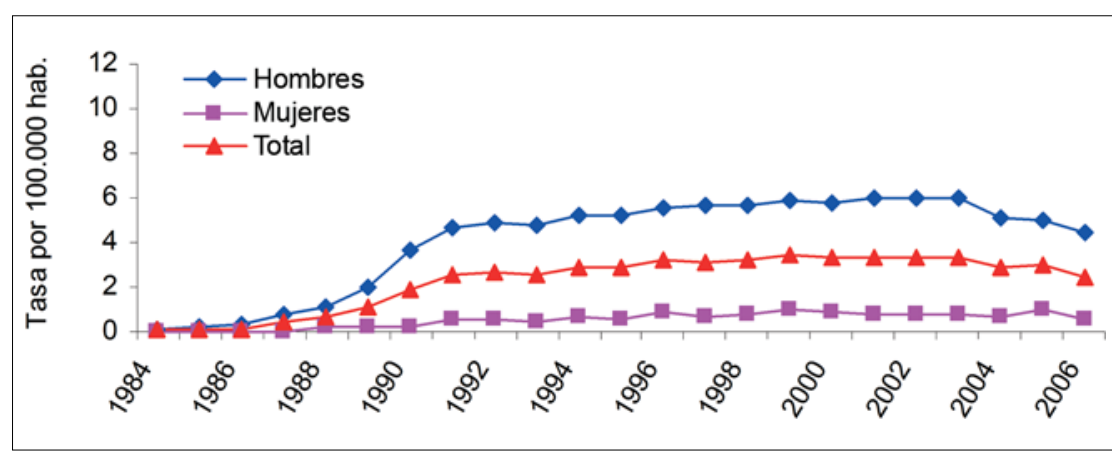

Figura 1. Tasa de notificación de SIDA por sexo y total país. Chile, 1984-2006.

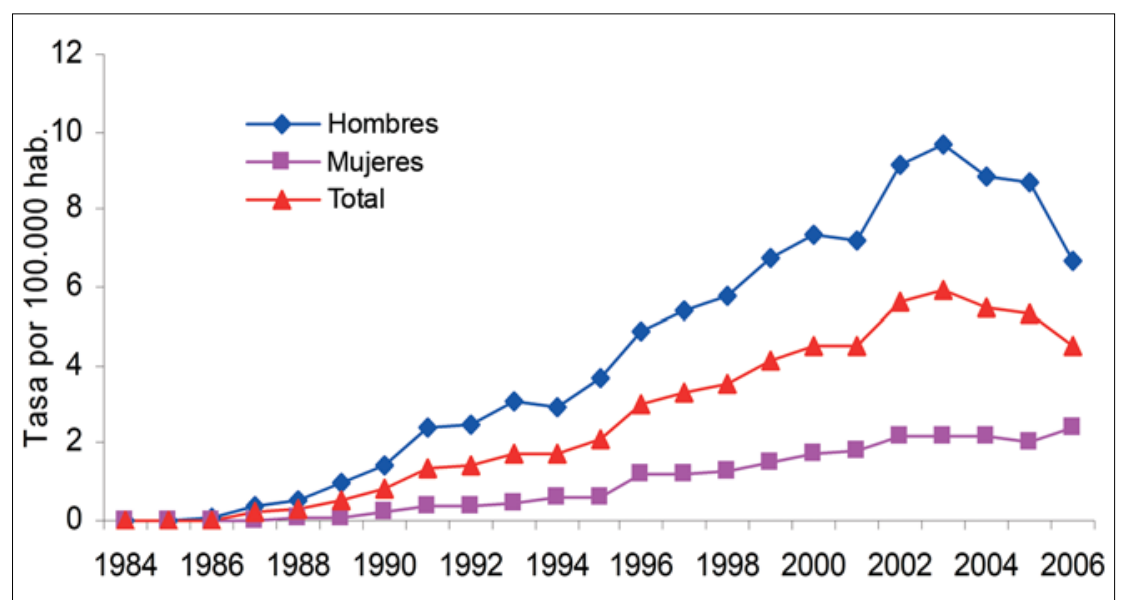

Figura 2. Tasa de notificación de infección por VIH según sexo y total país. Chile, 1984-2006.

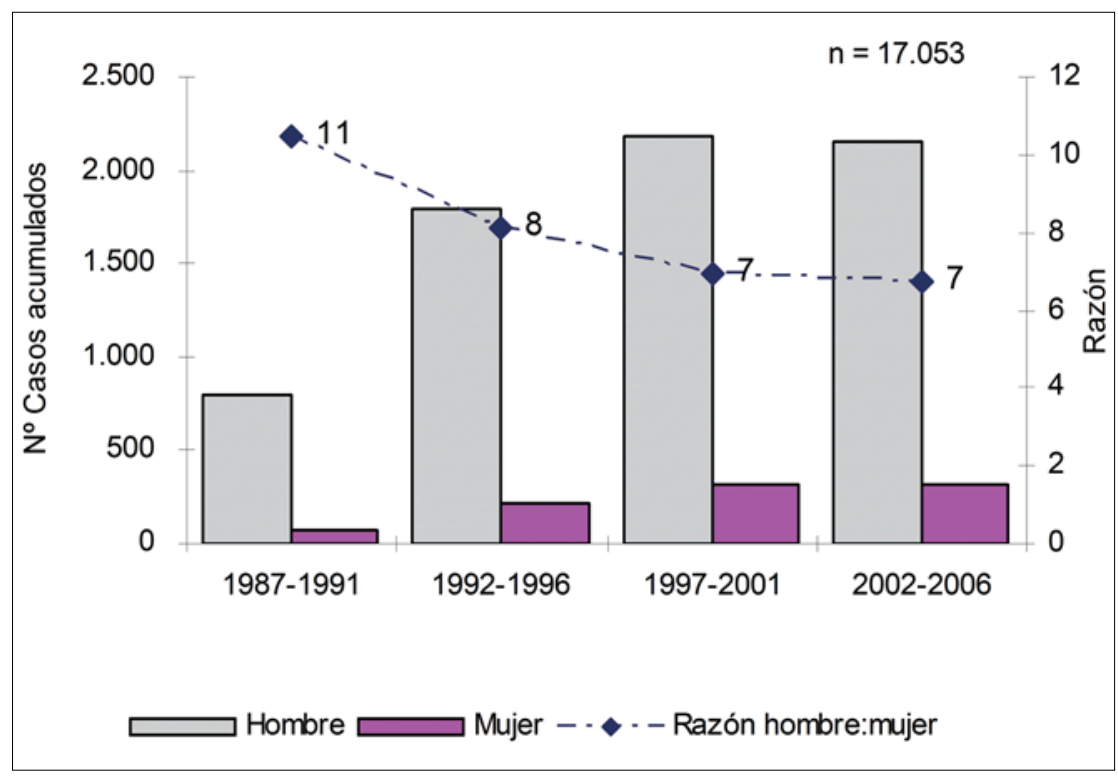

Figura 3. Casos de SIDA según sexo, y razón hombre mujer. Chile, 1987-2006. casos) están notificados como infección por VIH y 46\% (7.858 casos) como SIDA; en 139 personas no se dispone de información sobre la etapa diagnóstica.

\section{Tendencia 1984-2006}

SIDA: La tasa de notificación aumentó entre 1984 y 1991; a partir de 1992, las tasas variaron entre 2,6 y 3,5 casos por cien mil habitantes. Entre los años 2004 y 2006, se observó una disminución, más consistente entre los hombres (de 6,0 el 2003 a 4,4 casos por cien mil habitantes el año 2006) (Figura 1).

Infección por VIH: Se observa un aumento sostenido hasta el 2003, y luego la tasa tendió a disminuir el 2004 y 2006, a expensas de la disminución de notificación entre los hombres (de 9,7 el 2003 a 8,7 casos por cien mil habitantes el año 2006). Si bien, aún existe un retraso en la notificación, la disminución de ésta puede reflejar una disminución real de incidencia de casos o bien, a un fenómeno ocasionado por el retraso en las notificaciones (Figura 2).

\section{Distribución de personas con infección por VIH/SIDA según sexo y por quinquenios}

El análisis de los casos acumulados en el período 1987-2006, muestra que, en todos los quinquenios, el número de casos de hombres superó al de mujeres, tanto en SIDA (Figura 3) como en infección por VIH (Figura 4). Se observa también, que las mujeres aumentaron su proporción en el total de casos hasta 1996 (razón hombre: mujer en descenso), estabilizándose en los dos últimos quinquenios.

\section{Distribución de personas con infección por VIH/SIDA según edad}

Entre las notificaciones por SIDA, el mayor número de casos se concentró en los hombres de 30 y 39 años, mientras que en las mujeres los grupos de 20 a 29 años y 30 a 39 años concentraron similar número de casos (Figura 5).

$\mathrm{Al}$ analizar la evolución de los distintos grupos de edad, se observa que entre 20 y 29 años las tasas están descendiendo a partir de 1996, mientras que entre 30 y los 39 este descenso se produjo en el último quinquenio (Figura 6). Sobre los 40 años se observó un aumento en las tasas de notificación por SIDA.

Infección por VIH: Tanto en hombres como mujeres, la mayor concentración de casos se presentó entre 20 y 29 años de edad (Figura 7), un decenio antes que lo observado en SIDA. Esto concuerda con la historia natural de la enfermedad, donde el cambio de etapa de infección por VIH a SIDA se produce, aproximadamente, después de 10 años. Todos los grupos de edad aumentaron sus tasas de notificación a lo largo de los quinquenios estudiados (Figura 8). Los grupos con 
tasas más altas de notificación fueron los de 20-29 años y 30 a 39 años.

Distribución de personas con infección por VIH/ SIDA según nivel de escolaridad.

Se aprecia que los porcentajes de educación media y superior son más altos que los observados en la población general (Figuras 9 y 10).

\section{Distribución geográfica}

Las regiones de Tarapacá, Metropolitana y de Valparaíso muestran las tasas acumuladas máximas en el período, tanto en infección por VIH como en SIDA. La región con la tasa más baja de todo el país, para el SIDA, fue Aysén (Figura 11). Mientras que la región con la tasa más baja de infección por VIH fue Araucanía (Figura 12).

\section{Distribución de personas con infección por \\ VIH/SIDA según vía de exposición al virus}

En Chile, la principal vía de exposición al virus es la sexual (92\%). siendo la vía homosexual la más declarada (45\%). En alrededor de 5\% de los casos se desconoce la vía de exposición (Figura 13).

SIDA: En los últimos tres quinquenios, las vías de exposición homosexual y bisexual muestran una sostenida tendencia al descenso; en igual período, la vía heterosexual registra incrementos. La vía de exposición transfusional, el contagio asociado a hemofília y uso de drogas intravenosas, han descendido (Figura 14); mientras que la vía de transmisión vertical se ha mantenido relativamente estable entre 1,1 y 1,6\%.

Infección por VIH: A diferencia de los casos de SIDA, no se observaron cambios para la proporción de vía de transmisión homosexual, pero se observa descenso en la vía de transmisión bisexual. En la vía de transmisión heterosexual se produjo un aumento de $55 \%$ entre el primer y último quinquenio analizado (Figura 15).

\section{Distribución de factores de exposición según sexo}

SIDA: La distribución de los factores de exposición es muy diferente entre hombres y mujeres. En los hombres, la vía más frecuente fue homosexual y bisexual (72\%), mientras que en las mujeres la principal vía de exposición ha sido la heterosexual (86,4\%), en todos los quinquenios. En los hombres, las vías de exposición homosexual y bisexual concentraron el mayor número de casos (63,5\%); al igual que en las mujeres, se aprecia un aumento progresivo de la vía de exposición heterosexual (Figuras 16 y 17).

Infección por VIH: En las mujeres, la principal vía de exposición fue la heterosexual, en todos los quinquenios. En los hombres, las vías de exposición homo-

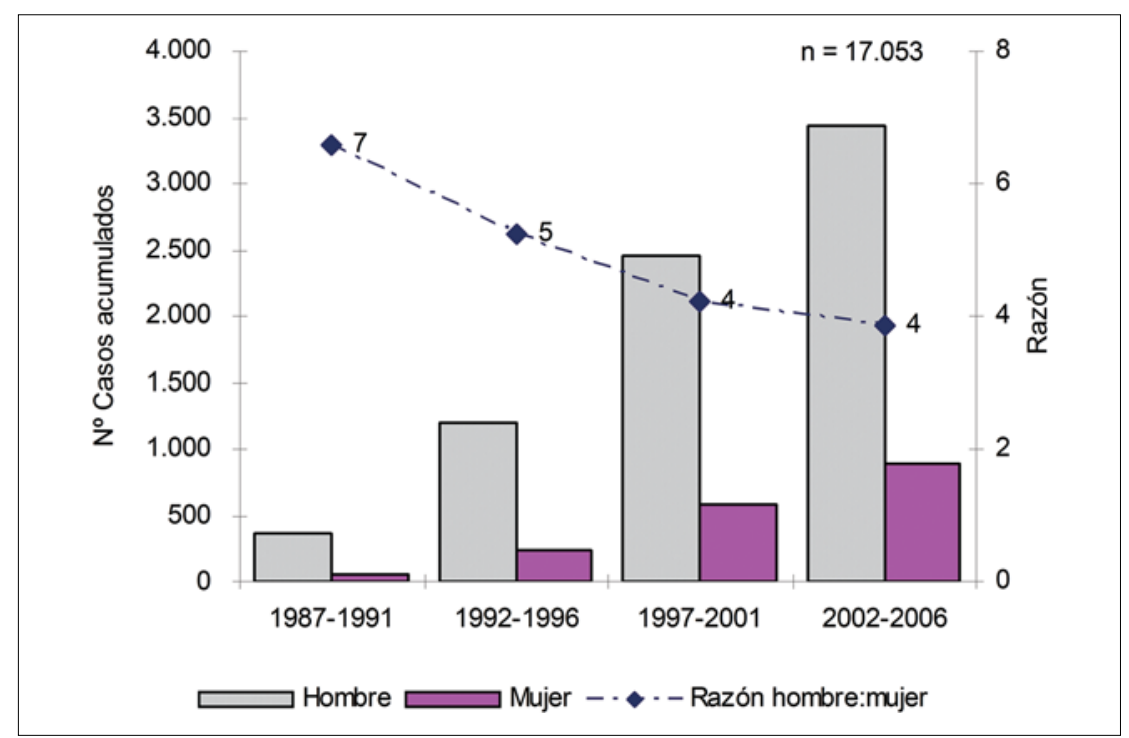

Figura 4. Casos de infección por VIH según sexo, y razón hombre mujer. Chile, 1987-2006.

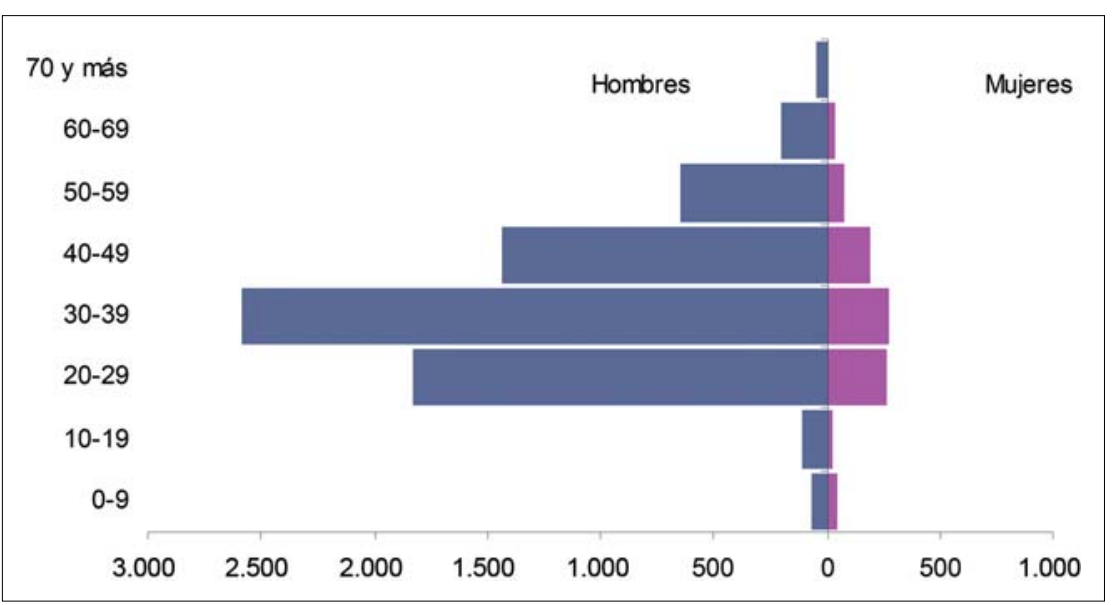

Figura 5. Casos acumulados de SIDA por grupo de edad y sexo. Chile, 1987-2006.

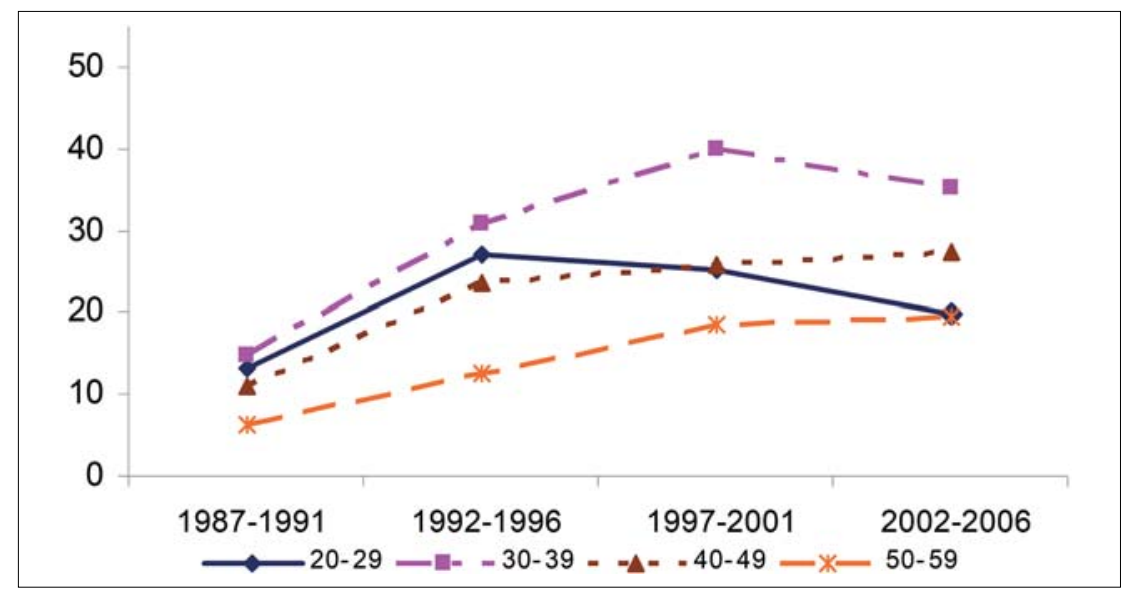

Figura 6. Tasa de notificación por SIDA según grupos de edad y quinquenio. Chile, 1987-2006. 


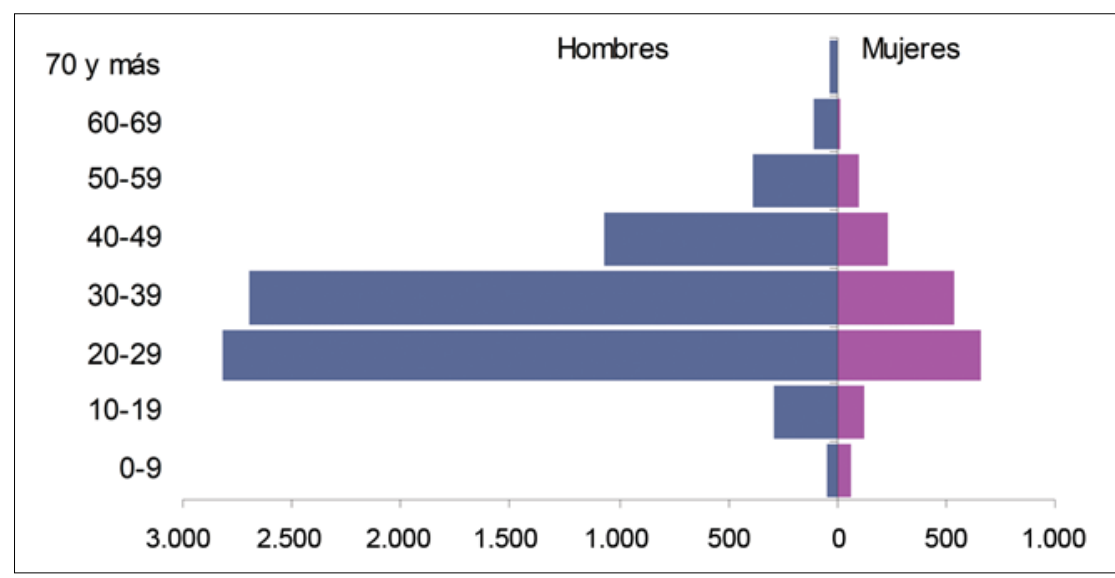

Figura 7. Casos acumulados de infección por VIH según grupo de edad y sexo. Chile, 1987-2006.

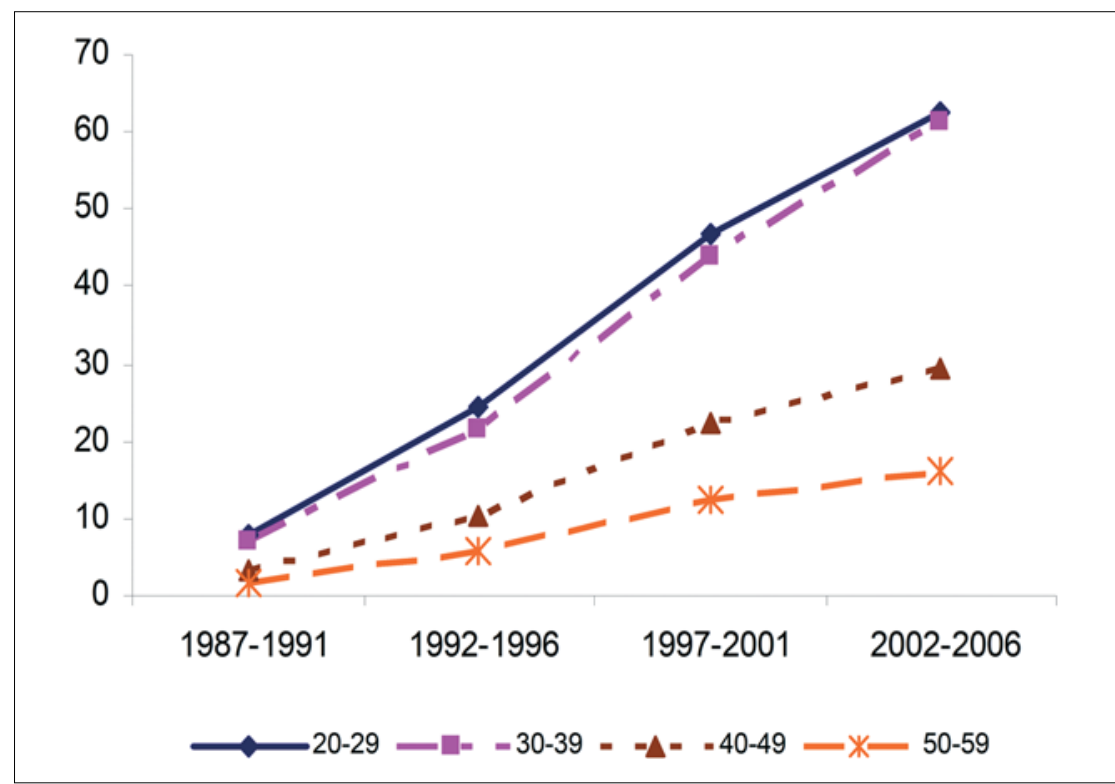

Figura 8. Tasa de notificación de infección por VIH según grupos de edad y quinquenio. Chile, 1987-2006

Figura 9. Distribución porcentual de casos de infección por VIH/SIDA según escolaridad. Chile, 1987-2006. sexual, heterosexual y bisexual concentraron el mayor número de casos (Figuras 18 y 19).

\section{Distribución de personas con infección por VIH/SIDA según etapa diagnóstica en la primera notificación}

Del total de casos de infección por VIH/SIDA notificados en Chile entre 1987 y 2006 (17.192), 53\% se notificó en etapa diagnóstica de infección por VIH, mientras que $46 \%$ fue notificado ya en etapa de SIDA. El porcentaje de mujeres que fue notificada en etapa de infección por VIH, es superior a los hombres en todos los quinquenios. Esto se podría deber a que las mujeres tienen más acceso a la oferta de examen a través del control de salud sexual y control de embarazo, entre otros (Figuras 20 y 21).

\section{Mortalidad por SIDA, Chile 1990-2005}

Entre 1990 y 2005, se produjeron en el país 5.288 defunciones por SIDA, correspondiendo $88 \%$ de ellas a hombres.

La tasa de mortalidad experimentó un aumento progresivo hasta 2001, cuando se observó la tasa más alta del período (3,6 por 100.000 hab.); en los últimos cuatro años (2002-2005), la mortalidad ha mostrado un descenso sostenido, llegando el año 2005 a 2,4 por 100.000 hab. Entre los años 2001 y 2005 disminuyó la mortalidad en hombres en 2,1 por cien mil, en tanto entre las mujeres la mortalidad se ha mantenido relativamente estable el último quinquenio (0,8 por 100.000 hab.), con una disminución puntual el año 2004 (Figura 22).

De acuerdo a los grupos de edad, la mortalidad más alta se observó entre los 30 y 60 años de edad, siendo el grupo entre 30 y 39 años el más afectado, seguido por el grupo de 40-49 y de 50-59 años (Figura 23).

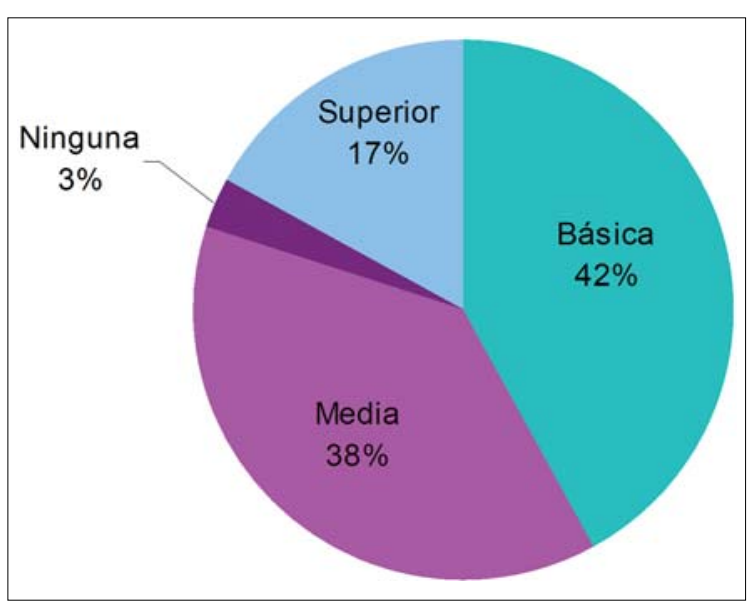

Figura 10. Distribución porcentual según escolaridad de la población general. Chile (censo) 2002. 


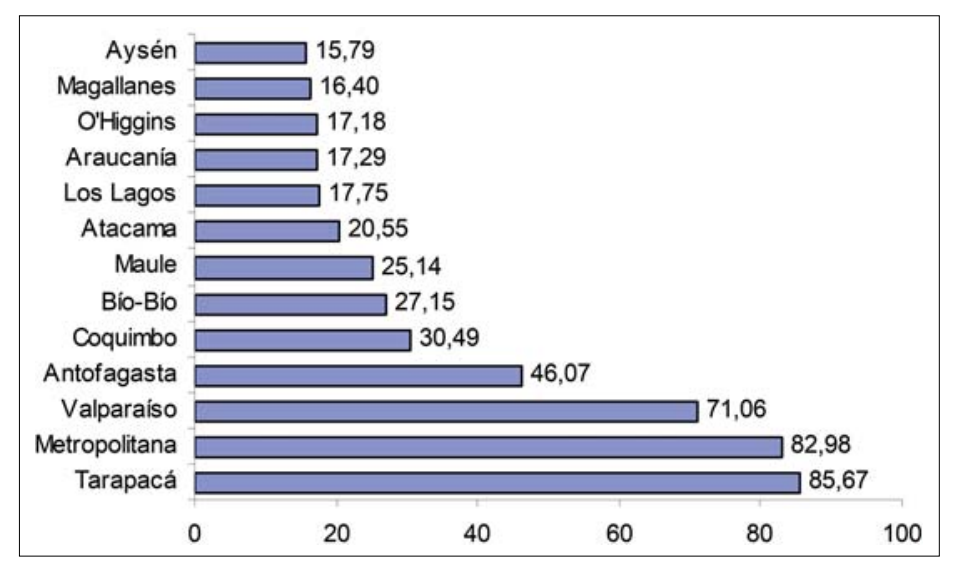

Figura 11. Tasa acumulada de notificación de SIDA según región. Chile, 19872006.

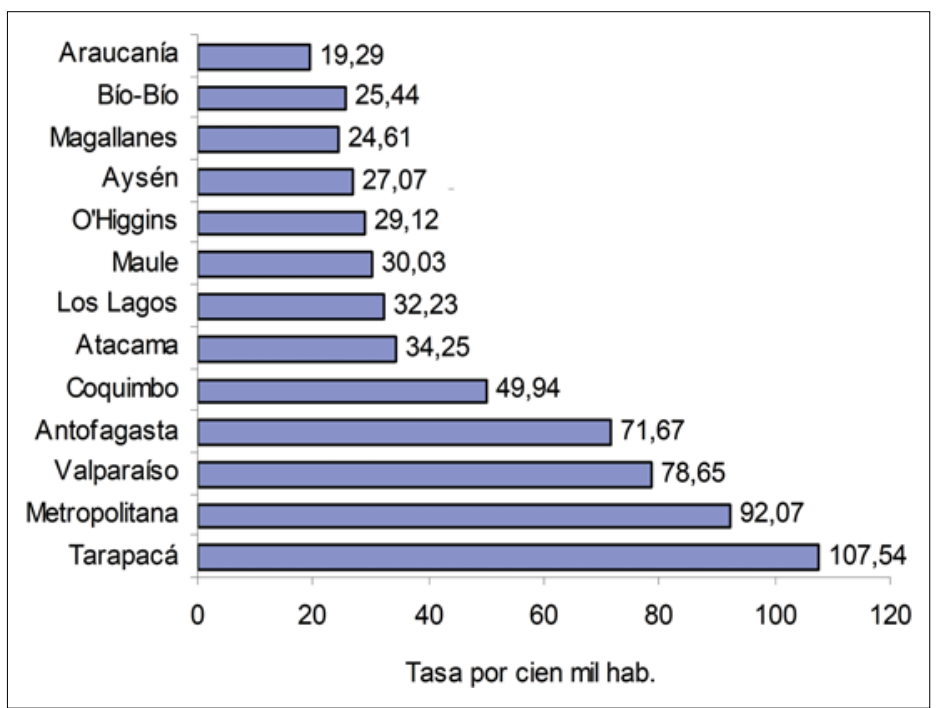

Figura 12. Tasa acumulada de notificación de infección por VIH según región. Chile, 1987-2006.

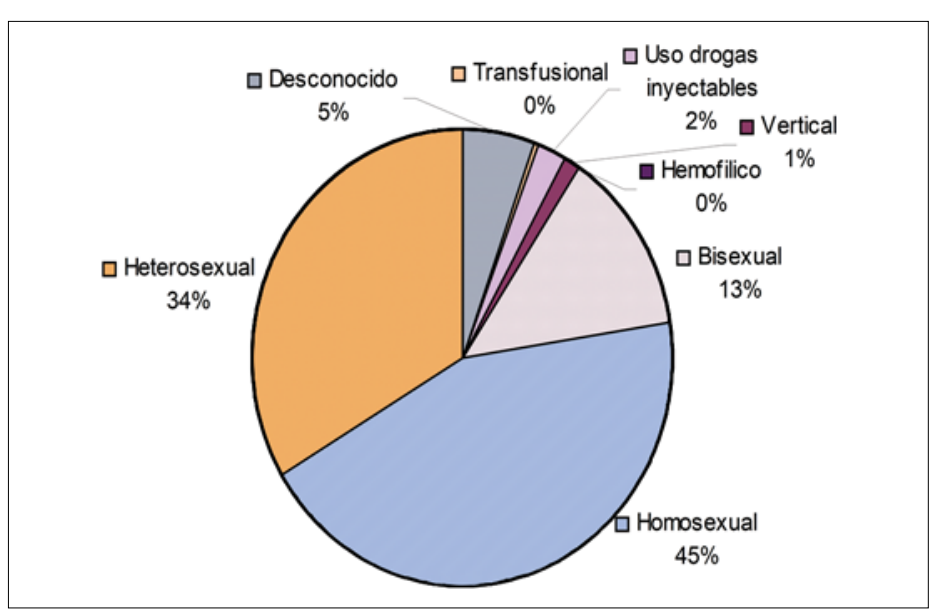

Figura 13. Distribución porcentual de casos acumulados de infección por VIH/ SIDA según vía de exposición. Chile, 1987-2006.

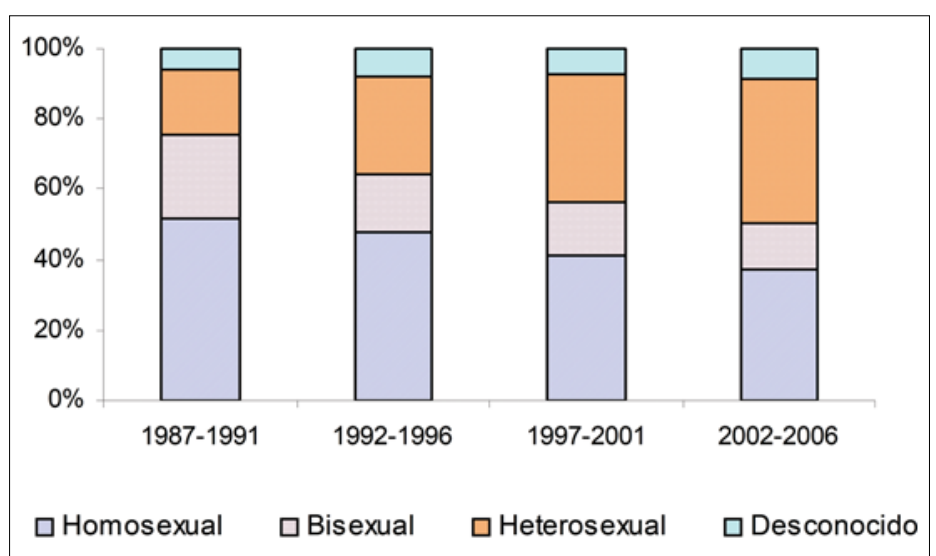

Figura 14. Distribución porcentual de casos de SIDA según factor de exposición y quinquenio. Chile, 1987-2006.

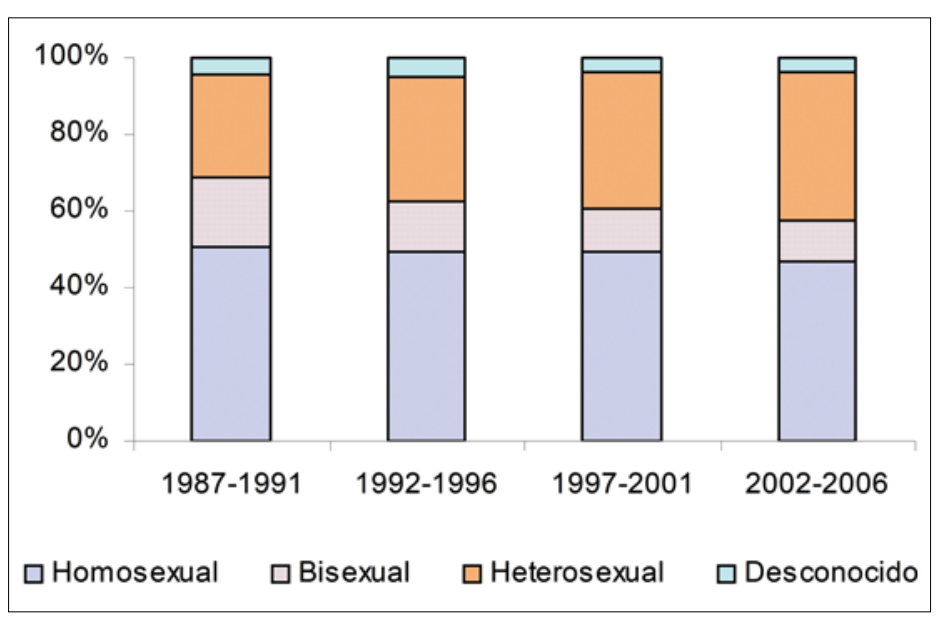

Figura 15. Distribución porcentual de casos de infección por VIH según factor de exposición y quinquenio. Chile, 1987-2006.

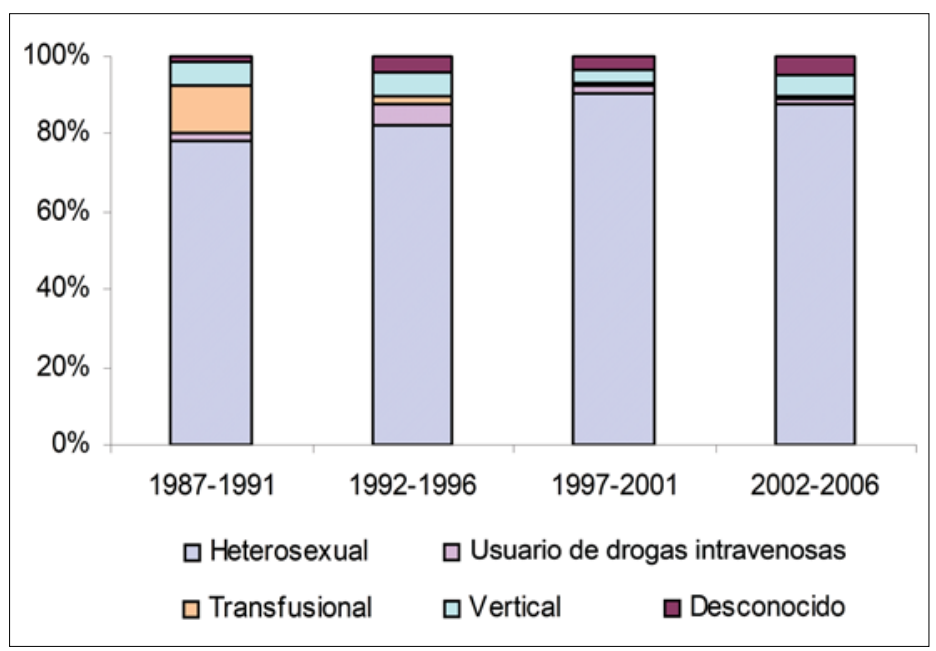

Figura 16. Distribución de casos de SIDA en mujeres según factor de exposición y quinquenio. Chile, 1987-2006. 


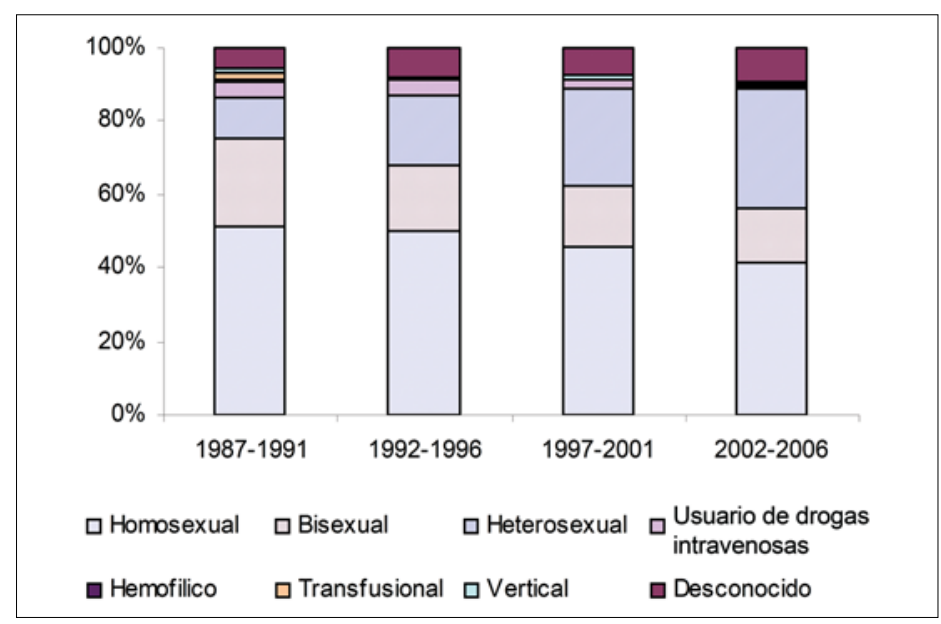

Figura 17. Distribución de casos de SIDA en hombres según factor de exposición y quinquenio. Chile, 1987-2006.

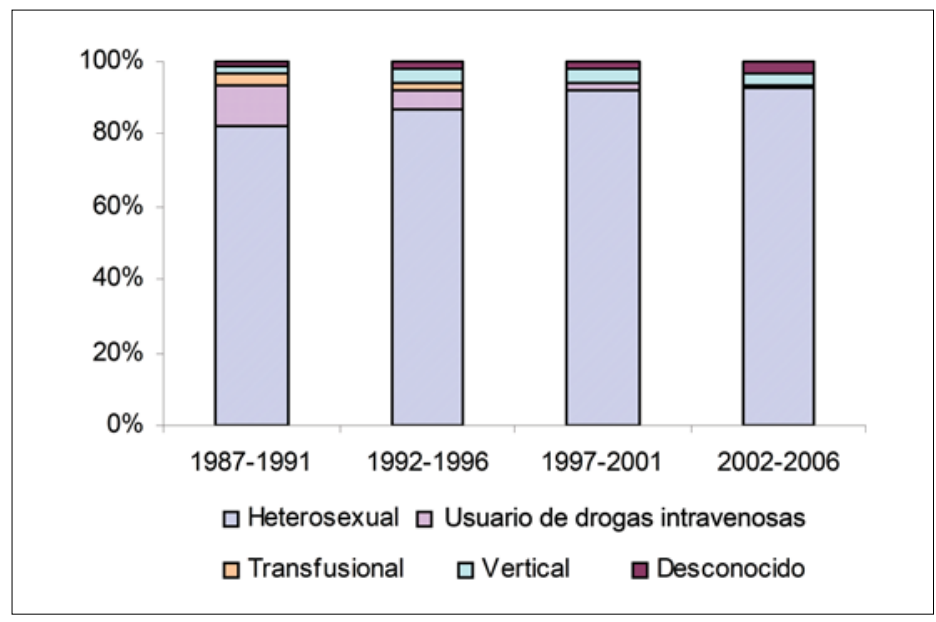

Figura 18. Distribución de casos de infección por VIH en mujeres según factor de exposición y quinquenio. Chile, 1987-2006.

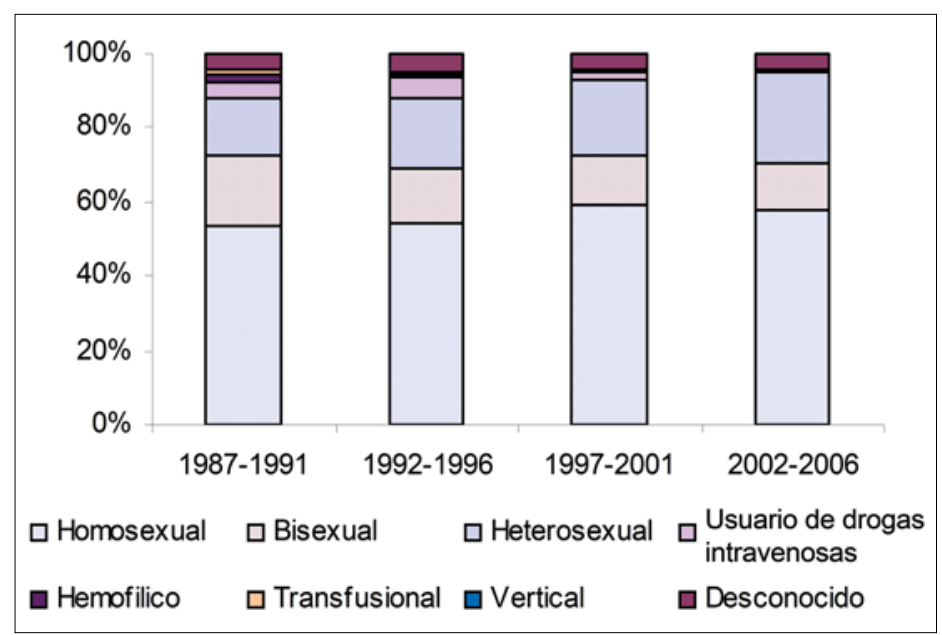

Figura 19. Distribución de casos de infección por VIH en hombres según factor de exposición y quinquenio. Chile, 1987-2006.

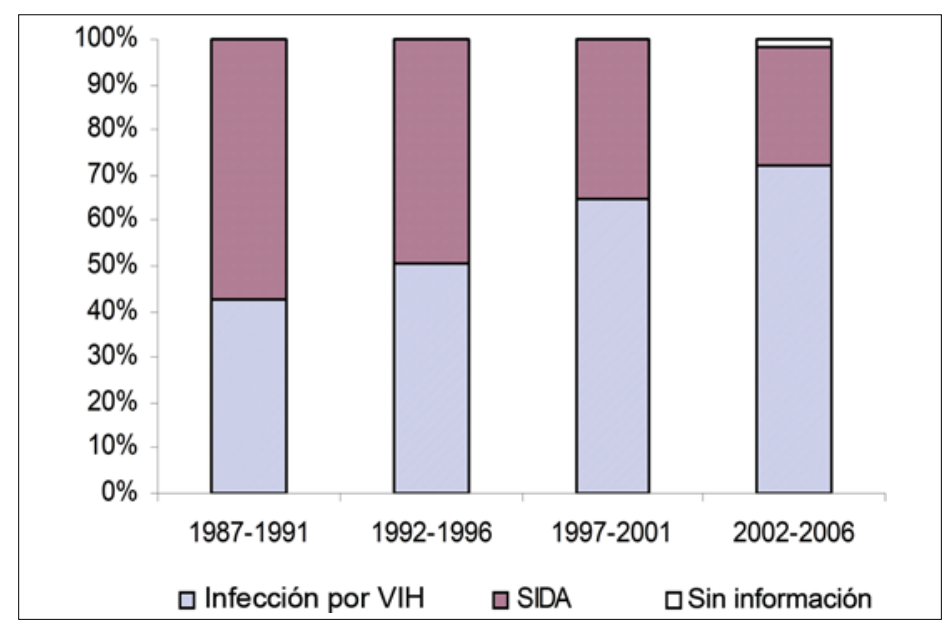

Figura 20. Distribución de casos de VIH/SIDA en mujeres por etapa diagnóstica en la $1^{\text {a }}$ notificación. Chile, 1987-2006.

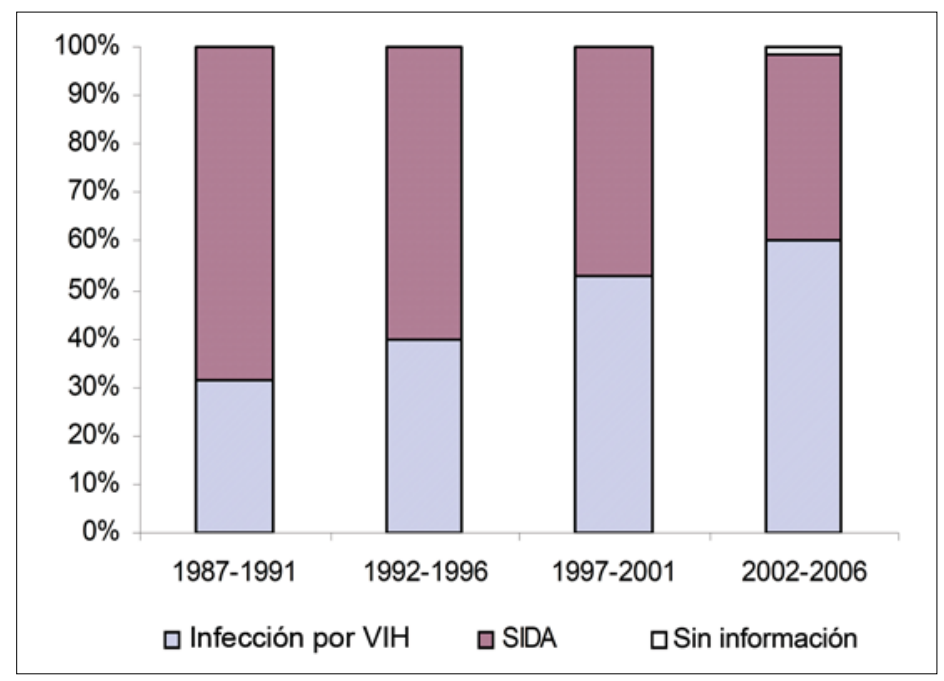

Figura 21. Distribución de casos de VIH/SIDA en hombres por etapa diagnóstica en la $1^{\text {a }}$ notificación. Chile, 1987-2006.

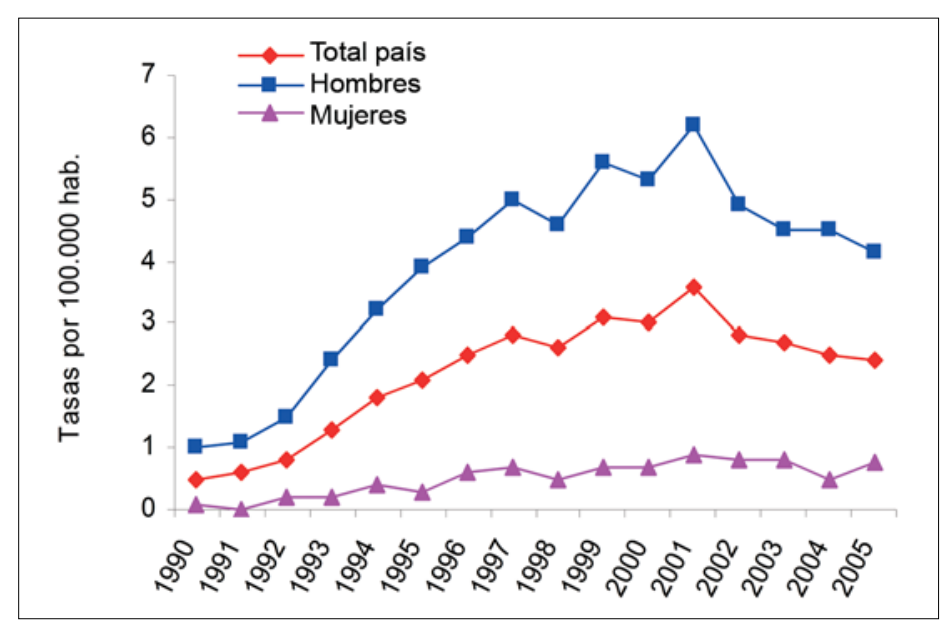

Figura 22. Mortalidad por SIDA, según sexo. Chile, 1990-2005. 
Entre 1998 y 2003 se observó un descenso de la razón de mortalidad hombre/mujer, es decir, estaría disminuyendo la diferencia de mortalidad entre hombres y mujeres, excepto el año 2004 (8,3 por 100.000 hab), para posteriormente en el 2005 disminuir a 5,4 (Tabla 2).

\section{Conclusiones}

En Chile, los primeros casos de SIDA se reportaron hace 23 años, y desde entonces hasta diciembre del año 2006, se han notificado 17.235 personas con infección por VIH o SIDA. Hasta el 2005, se registraron 5.288 personas fallecidas a causa del SIDA. Los últimos datos disponibles indican que las tasas de notificación para SIDA e infección por VIH en el año 2006 fueron 2,5 y 4,5 por cien mil habitantes, respectivamente, y la tasa de mortalidad por SIDA en el año 2005 fue de 2,4 por cien mil habitantes.

En Chile, la TARV se implementó en el año 1997; desde agosto de 2005 se incorporó dentro de la ley de Garantías Explícitas en Salud, GES, asegurándose por Ley el acceso de los beneficiarios FONASA e ISAPRES, a la TARV para $100 \%$ de los pacientes que la requieran ${ }^{8}$.

La epidemia afecta en Chile, principalmente, a adultos entre 20 y 39 años, en su mayoría de sexo masculino. Entre los infectados, la proporción de personas con educación media y superior es mayor que la observada en la población general y la principal vía de exposición al virus es la sexual (92\%), siendo la vía homosexual la más declarada (45\%).

Considerando las importantes variaciones en los patrones epidemiológicos de esta epidemia observada en la región de América Latina y también en Chile, según género, localidad geográfica y escolaridad, el análisis de la evolución de la enfermedad y la caracterización de la población afectada de infección por VIH/ SIDA, permiten orientar las medidas de prevención y control. Con este objetivo, en marzo de 2007 el Departamento de Epidemiología del MINSAL, elaboró y difundió la Circular B/51 Nº18 de vigilancia epidemiológica para infección por VIH/SIDA, que estableció el sistema de vigilancia de primera generación basada en la notificación individual de casos de infección por VIH, SIDA o muertes por SIDA. Asimismo, se desarrolló un sistema de notificación en línea para mejorar la oportunidad de la notificación y contribuir a la calidad de la información.

Agradecimientos: a Jeannette Dabanch P., por su revisión crítica del texto.

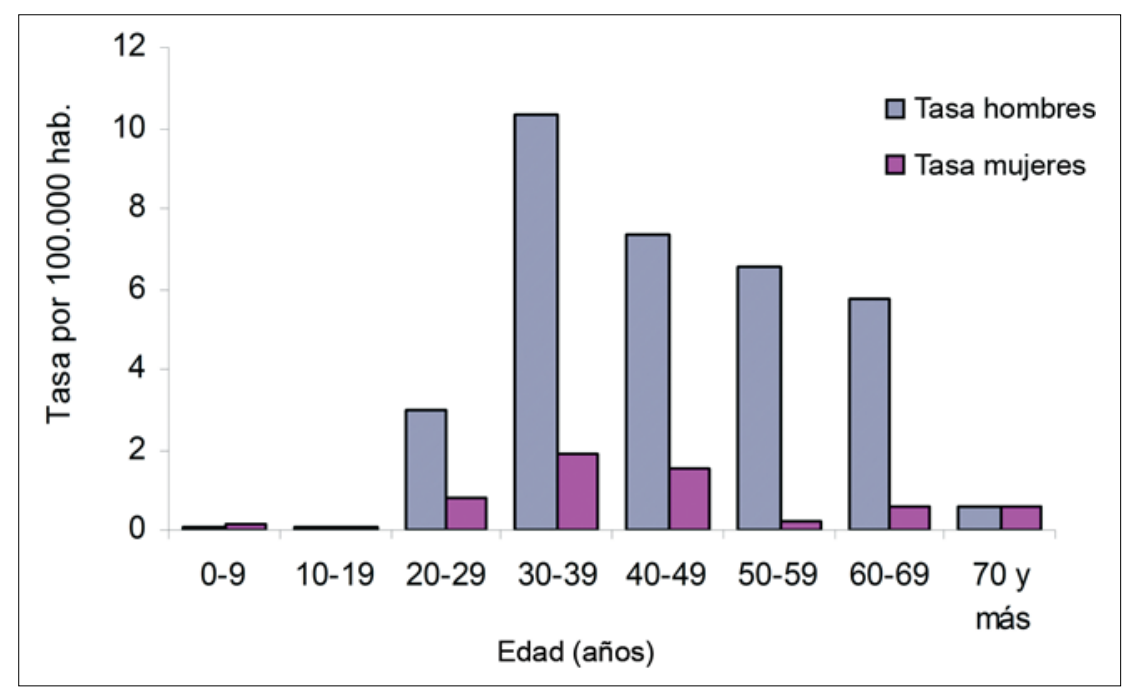

Figura 23. Mortalidad por SIDA según grupos de edad y sexo. Chile, 2005.

\begin{tabular}{|c|c|c|c|c|c|c|c|}
\hline \multirow[t]{2}{*}{ Año } & \multicolumn{2}{|c|}{ Ambos sexos } & \multicolumn{2}{|c|}{ Hombres } & \multicolumn{2}{|c|}{ Mujeres } & \multirow{2}{*}{$\begin{array}{l}\text { Razón } \\
\text { H:M }\end{array}$} \\
\hline & n def. & Tasa* & n def. & Tasa* & n def. & Tasa* & \\
\hline 1990 & 72 & 0,5 & 66 & 1,0 & 6 & 0,1 & 11 \\
\hline 1991 & 77 & 0,6 & 75 & 1,1 & 2 & 0,0 & 37,5 \\
\hline 1992 & 114 & 0,8 & 101 & 1,5 & 13 & 0,2 & 7,8 \\
\hline 1993 & 174 & 1,3 & 163 & 2,4 & 11 & 0,2 & 14,8 \\
\hline 1994 & 253 & 1,8 & 227 & 3,2 & 26 & 0,4 & 8,7 \\
\hline 1995 & 302 & 2,1 & 278 & 3,9 & 24 & 0,3 & 11,6 \\
\hline 1996 & 362 & 2,5 & 317 & 4,4 & 45 & 0,6 & 7,0 \\
\hline 1997 & 410 & 2,8 & 360 & 5,0 & 50 & 0,7 & 7,2 \\
\hline 1998 & 383 & 2,6 & 343 & 4,6 & 40 & 0,5 & 8,6 \\
\hline 1999 & 474 & 3,1 & 424 & 5,6 & 50 & 0,7 & 8,5 \\
\hline 2000 & 458 & 3,0 & 402 & 5,3 & 56 & 0,7 & 7,2 \\
\hline 2001 & 552 & 3,6 & 479 & 6,2 & 73 & 0,9 & 6,6 \\
\hline 2002 & 440 & 2,8 & 380 & 4,9 & 60 & 0,8 & 6,3 \\
\hline 2003 & 423 & 2,7 & 357 & 4,5 & 66 & 0,8 & 5,4 \\
\hline 2004 & 399 & 2,5 & 356 & 4,5 & 43 & 0,5 & 8,3 \\
\hline \multirow[t]{2}{*}{2005} & 395 & 2,4 & 333 & 4,1 & 62 & 0,8 & 5,4 \\
\hline & 5.288 & & 4.661 & & 627 & & \\
\hline \multicolumn{8}{|c|}{$\begin{array}{l}{ }^{1} \text { CIE-9 (hasta 1996) : 279,5, } 2 \\
{ }^{*} \text { Tasa por cien mil habitantes } \\
\text { Fuente DEIS, MINSAL } 2007\end{array}$} \\
\hline
\end{tabular}




\section{Referencias}

1.- Ministerio de Salud, DIPLAS, Departamento de Epidemiología. Evolución del VIH-SIDA en Chile, 1987-2006.

2. Programa conjunto de las Naciones Unidas sobre el VIH/SIDA (ONUSIDA) y la Organización Mundial de la Salud (OMS) 2007.

3.- Ministerio de Salud. Reglamento sobre notificación de enfermedades transmisibles de declaración obligatoria. $\mathrm{N}^{\circ} 158$, Octubre 2004.

4.- Ministerio de Salud, Departamento de Estadísticas e Información en Salud, Certificados de Defunción, años 1990 al 2005.

5.- Ministerio de Salud, DIPLAS, Departamento de Epidemiología, Circular B51/Nº18, marzo 2007.
6.- Ministerio de Salud, Departamento de Estadísticas e Información en Salud, "Encuesta Epidemiológica de caso de infección por VIH/SIDA" años 1984 al 2006.

7.- Instituto Nacional de Estadísticas (INE), Censo 2002.

8.- Ministerio de Salud, Ley 19.966 de régimen general de garantías explícitas en salud, Chile septiembre 2004. 